\title{
Use of protamine sulfate during transfemoral transcatheter aortic valve implantation - a preliminary assessment of administration rate and impact on complications
}

\author{
Karol Zbroński ${ }^{1}$, Kajetan Grodecki ${ }^{1}$, Roksana Gozdowska ${ }^{1}$, Szymon Jędrzejczyk ${ }^{1}$, Ewa Ostrowska ${ }^{1}$, \\ Julia Wysińska ${ }^{1}$, Bartosz Rymuza ${ }^{1}$, Piotr Scisło ${ }^{1}$, Radosław Wilimski ${ }^{2}$, Janusz Kochman ${ }^{1}$, Krzysztof J. Filipiak ${ }^{1}$, \\ Grzegorz Opolski ${ }^{1}$, Zenon Huczek ${ }^{1}$
}

${ }^{1}$ First Department of Cardiology, Medical University of Warsaw, Warsaw, Poland

${ }^{2}$ Department of Cardiac Surgery, Medical University of Warsaw, Warsaw, Poland

Adv Interv Cardiol 2020; 16, 3 (61): 306-314 DOI: https://doi.org/10.5114/aic.2020.99266

\begin{abstract}
A bstract
Introduction: Bleeding complications after transcatheter aortic valve implantation (TAVI) are an important issue and negatively affect survival. The rate and impact of protamine sulfate (PS) administration on bleeding complications after TAVI remain unclear.

Aim: To assess the impact of PS on bleeding complications after TAVI.

Material and methods: Between March 2010 and November 2016 two hundred fifty-eight patients qualified for TAVI in one academic center were screened. Baseline, procedural and follow-up data up to 30 days were collected and analyzed. The primary endpoint (PE) was major bleeding according to the Valve Academic Research Consortium up to $48 \mathrm{~h}$ after the procedure.

Results: Overall, 186 patients (96 females, mean age: 80 years) met the inclusion criteria. Thirty-nine (21\%) subjects received PS. PE occurred in $24.7 \%$ of the study population. There were no significant differences in terms of the PE rate between the groups (25.6\% in the PS group and $24.7 \%$ in the remaining cohort, $p=0.9$, odds ratio $(\mathrm{OR})=1.05$, confidence interval $(\mathrm{Cl}): 0.47-2.4$, $p=0.9)$. Multivariate analysis identified female gender $(\mathrm{OR}=2.2, \mathrm{Cl}: 1.08-4.4, p=0.03)$ as an independent predictor of PE occurrence. Similarly, female gender $(\mathrm{OR}=2, \mathrm{Cl}: 1.06-3.84, p=0.03)$ as well as general anesthesia $(\mathrm{GA}, \mathrm{OR}=2.23, \mathrm{Cl}: 1.13-4.63$, $p=0.02)$ and dose of unfractionated heparin per kilogram (UFH/kg, OR $=1.02, \mathrm{Cl}: 1-1.03$ per $1 \mathrm{IU}$ increment, $p=0.02)$ predicted the occurrence of a composite of major and minor bleeding.

Conclusions: In this analysis, PS administration did not decrease the PE rate. Female gender predicted PE occurrence. Randomized, placebo-controlled trials are required to accurately assess the impact of PS.
\end{abstract}

Key words: protamine sulfate, bleeding complications, transcatheter aortic valve implantation.

S u m m a ry

Bleeding complications after transcatheter aortic valve implantation (TAVI) are an important issue and negatively affect survival. The rate and impact of protamine sulfate (PS) administration on bleeding complications after TAVI remain unclear. In this analysis, PS administration did not decrease the primary endpoint (PE) rate. Female gender predicted PE occurrence. Randomized, placebo-controlled trials are required to accurately assess the impact of PS.

\section{Introduction}

Transcatheter aortic valve implantation (TAVI) is a rapidly emerging standard of care in patients with severe, symptomatic aortic stenosis, initially reserved for high surgical risk and inoperable patients, with the most recent studies showing a clear benefit in the low surgical risk cohort as well [1]. Numerous aspects of the pre-, peri- and post-procedural care have been studied and assessed in a wide array of randomized and non-randomized trials. However, reversal of unfractionated heparin

\section{Corresponding author:}

Karol Zbroński, First Department of Cardiology, Medical University of Warsaw, 1a Banacha St, 02-097 Warsaw, Poland, phone: +48 2259919 58, fax: +48 2259919 57, e-mail: karol.zbronski@gmail.com

Received: 2.04.2020, accepted: 18.05.2020. 
(UFH) with protamine sulfate (PS) has never been thoroughly analyzed.

The current recommendation regarding reversal of UFH with PS is based on the expert consensus from 2012 [2], which recommends use of UFH in order to achieve activated clotting time $(\mathrm{ACT})>300 \mathrm{~s}$ as well as UFH reversal with PS in the case of TAVI via transapical access as well as transfemoral access with the exception of cases with minimal bleeding risk. Nonetheless, the clinical practice varies between centers - some use PS routinely [3], while others do so only in selected cases [4].

The actual impact of PS on reduction of bleeding complications is unknown. Furthermore, a pro-thromboembolic effect of PS cannot be excluded [5-7]. Both bleeding (major and life-threatening according to Valve Academic Research Consortium (VARC) criteria) [8] and thromboembolic complications increase mortality after TAVI [9], whereas minor bleeding complications may prolong the hospital stay. The occurrence of these complications in international TAVI registries in 30-day observation ranges from $9.7 \%$ in the case of major bleeding [10], $4.7 \%$ in the case of life-threatening bleeding [11] and 5\% in the case of strokes [12]. There are no randomized studies assessing the impact of PS on frequency of bleeding and thromboembolic complications after TAVI, its side-effects and influence on mortality.

\section{Aim}

In order to appropriately plan a randomized controlled trial, we sought to first assess the frequency and impact of PS administration in this single-center retrospective analysis.

\section{Material and methods}

\section{Study design and population}

Two hundred and fifty-eight consecutive inoperable or high-risk patients with severe symptomatic aortic stenosis (aortic valve area (AVA) $<1.0 \mathrm{~cm}^{2}$ or indexed valve area less than $0.6 \mathrm{~cm}^{2} / \mathrm{m}^{2}$ or mean gradient $>40 \mathrm{~mm} \mathrm{Hg}$ or maximum jet velocity $>4.0 \mathrm{~m} / \mathrm{s}$ or velocity ratio $<0.25)$, who after the heart team decision underwent TAVI in an academic center between March 2010 and March 2016, were screened. The local ethics committee was informed about the study as per its guidelines for retrospective analyses.

All the procedures were performed in a hybrid operating room under general anesthesia (GA) or local anesthesia with conscious sedation. Balloon-, mechanically and self-expandable aortic valve prostheses of the first and second generation were used. Patients undergoing surgical cutdown as well as percutaneous access with a closure device were included. After obtaining the vascular access, all patients received a bolus of 5000 IU of UFH followed by additional boluses if necessary to achieve the target ACT of > $300 \mathrm{~s}$. The administration of PS was at the operators' discretion and the dosage was based on the amount of UFH administered as well as the ACT at the end of the procedure. In the case of antithrombotic treatment before and after TAVI, patients without indications for chronic oral anticoagulation (OAC) were given loading doses of $300 \mathrm{mg}$ of aspirin and clopidogrel within $24 \mathrm{~h}$ before TAVI, and then continued $75 \mathrm{mg}$ daily after the procedure. In patients requiring chronic OAC, the treatment was stopped 2-3 days before the procedure in order to obtain an international normalized ratio (INR) value $<2$ in the case of vitamin $\mathrm{K}$ antagonists (VKA) and 1-2 days before the procedure depending on the renal function in the case of non-vitamin $\mathrm{K}$ antagonists. After TAVI oral anticoagulation was restarted as soon as deemed safe, with additional bridging with low-molecular weight heparin in patients receiving VKA.

The exclusion criteria were other-than-transfemoral access, conversion to aortic valve replacement, and procedural death defined as death during or immediately after the procedure.

\section{Definitions and endpoints}

Bleeding complications were defined according to Valve Academic Research Consortium 2 (VARC-2) criteria. Coronary artery disease was defined as a history of percutaneous coronary intervention $(\mathrm{PCI})$, post coronary artery bypass grafting (CABG) status or presence of one or more lesions of the epicardial coronary vessels with $>70 \%$ diameter stenosis in arteries larger than $2 \mathrm{~mm}$ (> 50\% for left main stem).

The primary endpoint (PE) of the study was a major bleeding complication according to VARC-2 at $48 \mathrm{~h}$ after the procedure. The secondary endpoints were the composite of major and minor bleeding complications according to VARC- 2 at $48 \mathrm{~h}$ after the procedure and thromboembolic events (stroke, transient ischemic attack, myocardial infarction) within $48 \mathrm{~h}$ after the procedure.

\section{Statistical analysis}

Continuous variables, expressed as means \pm SD, were compared between the PS and control groups using Student's $t$-test or the Mann-Whitney $U$-test depending on the distribution pattern. The Shapiro-Wilk test was used to confirm or reject normal distribution of each continuous variable. Categorical variables, expressed as counts and percentages, were compared using the $\chi^{2}$ test or Fisher's exact test, as appropriate. An univariate backwards likelihood ratio logistic regression model was used to identify predictors of the primary and secondary endpoints. Variables from the univariate analysis and baseline variables that were different between groups (with a $p$-value $\leq 0.10$ difference) were included in the multivariate analysis. Results are presented as odds ratio (OR) with 95\% confidence interval. All probability values reported are 2 -sided and a value $<0.05$ was considered 
to be significant. All data were processed using the SPSS software, version 22 (IBM SPSS Statistics, New York, US).

\section{Results}

\section{Population}

Of the 258 consecutive patients screened, 54 (21\%) underwent TAVI via other-than-transfemoral access, 15 (5.8\%) patients required conversion to surgical aortic valve replacement or died during or immediately after the procedure and in $3(1.1 \%)$ definite data about periprocedural anticoagulation and PS use were missing. The study flow-chart is presented in Figure 1 . The overall study population consisted of 186 patients. The mean age was 80.1 years, there were 96 (52\%) females, almost $75 \%$ of patients had hypertension, $37 \%$ had diabetes and almost half (48.4\%) were in New York Heart Association (NYHA) class III or IV. In over half (55.9\%) of the procedures a vascular closure device was used (Prostar (Abbott Vascular Inc.) in 90\% and Proglide (Abbott Vascular Inc.) in 10\% of cases). Detailed baseline data are shown in Table I.

\section{Protamine sulfate administration}

Thirty-nine $(21 \%)$ patients received protamine sulfate at the end of the procedure in order to reverse the unfractionated heparin effect. The mean dose was

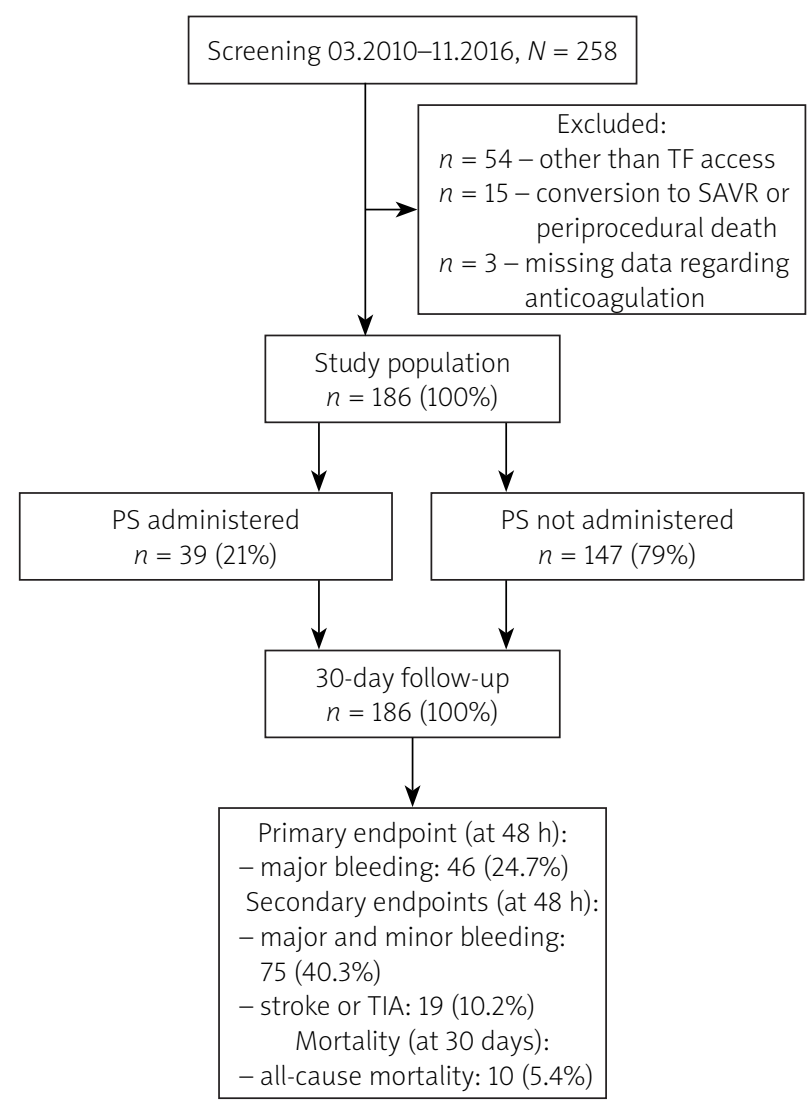

Figure 1. Study flowchart
$0.48 \mathrm{mg} / 100 \mathrm{IU}$ of UFH. The group receiving PS had higher ejection fraction ( $56.3 \%$ vs. $50.1 \%, p=0.02)$, received more UFH/kg (99.9 vs. $90.3 \mathrm{IU}, p=0.01$ ) and more often underwent the procedure via percutaneous access with a closure device ( $82.1 \%$ vs. $49 \%, p \leq 0.001$, Table I).

\section{Endpoints}

The primary endpoint of major bleeding was observed in 46 patients $(24.7 \%$ of the entire population; in the majority of the cases $(n=43)$ the bleeding was related to the access site). The composite endpoint of major and minor bleeding was observed in 75 patients $(40.3 \%$ of the study cohort, 29 minor bleeding complications $(15.6 \%$ of the entire group) - all related to the access site). There were 3 life-threatening bleeding complications (1.6\%) and 54 patients required transfusion of blood products (29\%). Thirteen strokes and seven transient ischemic attacks were observed (7\% and 3\%, respectively). The 30-day allcause mortality was $5.4 \%$.

In a multivariate analysis of the primary endpoint, only female gender (odds ratio $(O R)=2.2$, confidence interval ( $\mathrm{Cl}$ ) 1.08-4.4, $p=0.03$ ) was identified as an independent predictor of PE occurrence (Table II). In a multivariate analysis of the secondary endpoint encompassing major and minor bleeding again female gender $(\mathrm{OR}=2, \mathrm{Cl}: 1.06-3.84, p=0.03)$ as well as $\mathrm{GA}$ $(\mathrm{OR}=2.23, \mathrm{Cl}: 1.13-4.63, p=0.02)$ and number of international units (IU) of UFH per kg (OR $=1.02, \mathrm{Cl}$ : $1-1.03$, $p=0.02$, per $1 \mathrm{IU} / \mathrm{kg}$ increment) were independently associated with the endpoint occurrence (Table III). Multivariate analysis of occurrence of ischemic events demonstrated a significant negative impact of stroke or TIA in the past $(\mathrm{OR}=3.85, \mathrm{Cl}: 1.31-11.3, p=0.01)$ and a protective effect of balloon- or mechanically expandable prosthesis use (OR $=0.25, \mathrm{Cl}: 0.07-0.92, p=0.04)$. Protamine sulfate administration resulted in a numerically higher stroke or TIA rate $(\mathrm{OR}=2.46, \mathrm{Cl}$ : 0.89-6.75, $p=0.08$ ) (Table IV).

\section{Protamine sulfate and endpoints}

PS administration did not impact the occurrence of the remaining endpoints (Table V). More detailed subgroup analysis failed to demonstrate a protective effect of PS administration and PE occurrence in females (OR = $0.51, \mathrm{Cl} 0.2-1.31, p=0.16$ ), patients who received more than $92 \mathrm{IU}$ of UFH per $\mathrm{kg}$ (mean UFH/kg value of the entire cohort, $\mathrm{OR}=0.52, \mathrm{Cl}: 0.18-1.55, p=0.24)$ and patients who underwent a procedure with a closure device $(\mathrm{OR}=0.91, \mathrm{Cl}: 0.39-2.11, p=0.8)$.

\section{Discussion}

Impact of protamine sulfate on bleeding and thromboembolic complications

The main finding of our study is that PS administration during transfemoral TAVI did not decrease the rate of 
Table I. Baseline and procedural characteristics of the study population along with endpoint rates

\begin{tabular}{|c|c|c|c|c|}
\hline Parameter & $\begin{array}{c}\text { Total } \\
(N=186)\end{array}$ & $\begin{array}{c}\text { PS } \\
(n=39,21 \%)\end{array}$ & $\begin{array}{c}\text { No PS } \\
(n=147,79 \%)\end{array}$ & $P$-value \\
\hline \multicolumn{5}{|l|}{ Demographics: } \\
\hline Female gender, $n(\%)$ & $96(51.6)$ & $24(61.5)$ & $72(49)$ & 0.16 \\
\hline Age, mean $\pm S D$ [years] & $80.1 \pm 7$ & $79.7 \pm 9$ & $80.2 \pm 7$ & 0.69 \\
\hline \multicolumn{5}{|l|}{ Baseline characteristics: } \\
\hline $\mathrm{BMI}$, mean $\pm \mathrm{SD}\left[\mathrm{kg} / \mathrm{m}^{2}\right]$ & $26.4 \pm 4$ & $26.1 \pm 5$ & $26.5 \pm 4$ & 0.64 \\
\hline $\mathrm{BSA}$, mean $\pm \mathrm{SD}\left[\mathrm{m}^{2}\right]$ & $1.78 \pm 0.2$ & $1.74 \pm 0.2$ & $1.79 \pm 0.2$ & 0.10 \\
\hline Hypertension, $n(\%)$ & $139(74.7)$ & $33(84.6)$ & $106(72.1)$ & 0.11 \\
\hline Diabetes, $n(\%)$ & $68(36.6)$ & $16(41)$ & $52(35.4)$ & 0.52 \\
\hline GFR $<30 \mathrm{ml} / \mathrm{min}, n(\%)$ & $17(9.1)$ & $3(7.7)$ & $14(9.5)$ & 0.72 \\
\hline History of bleeding, $n(\%)$ & $13(7)$ & $5(12.8)$ & $8(5.4)$ & 0.11 \\
\hline Coronary artery disease, $n$ (\%) & $110(59.1)$ & $18(16.4)$ & $92(62.6)$ & 0.06 \\
\hline Prior cardiac surgery, $n(\%)$ & $25(13.4)$ & $5(12.8)$ & $20(13.6)$ & 0.89 \\
\hline History of stroke/TIA, n (\%) & $31(16.7)$ & $8(20.5)$ & $23(15.6)$ & 0.47 \\
\hline Atrial fibrillation, $n(\%)$ & $66(35.5)$ & $15(38.5)$ & $51(34.7)$ & 0.66 \\
\hline COPD, $n(\%)$ & $35(18.8)$ & $8(20.5)$ & $27(18.4)$ & 0.76 \\
\hline Prior pacemaker implantation, $n(\%)$ & $32(17.2)$ & $8(20.5)$ & $24(16.3)$ & 0.54 \\
\hline NYHA class 3-4, $n(\%)$ & $90(48.4)$ & $14(35.9)$ & $76(51.7)$ & 0.08 \\
\hline LVEF, mean \pm SD \% & $51.9 \pm 14$ & $56.3 \pm 11$ & $50.1 \pm 14$ & 0.02 \\
\hline LVEF $<40 \%$ & $44(23.7)$ & $4(10.3)$ & $40(27.2)$ & 0.03 \\
\hline$M R \geq 3$ & $42(22.6)$ & $8(20.5)$ & $34(23.1)$ & 0.73 \\
\hline Serum creatinine, mean \pm SD [mg/dl] & $1.4 \pm 0.9$ & $1.3 \pm 0.9$ & $1.4 \pm 0.9$ & 0.81 \\
\hline Hemoglobin, mean \pm SD [g/dl] & $12.3 \pm 2$ & $12 \pm 1$ & $12.3 \pm 2$ & 0.24 \\
\hline \multicolumn{5}{|l|}{ Procedural data: } \\
\hline General anesthesia, $n(\%)$ & $129(69.4)$ & $24(61.5)$ & $105(71.4)$ & 0.23 \\
\hline Closure device, $n(\%)$ & $104(55.9)$ & $32(82.1)$ & $72(49)$ & $<0.001$ \\
\hline $\mathrm{UFH}$, mean $\pm \mathrm{SD}\left[\times 10^{3} \mathrm{IU}\right]$ & $6.3 \pm 2$ & $6.8 \pm 2$ & $6.2 \pm 2$ & 0.09 \\
\hline $\mathrm{UFH} / \mathrm{kg}$, mean $\pm \mathrm{SD}[\mathrm{IU}]$ & $92.3 \pm 21$ & $99.9 \pm 26$ & $90.3 \pm 19$ & 0.01 \\
\hline $\begin{array}{l}\text { Balloon-expandable and mechanically } \\
\text { expandable prosthesis, } n(\%)\end{array}$ & $69(37.1)$ & $14(35.9)$ & $55(37.4)$ & 0.86 \\
\hline AR post-TAVI, grade $\geq 3, n(\%)$ & $32(17.2)$ & $7(17.9)$ & $25(17)$ & 0.89 \\
\hline \multicolumn{5}{|l|}{ Endpoints: } \\
\hline 30-day all-cause mortality & $10(5.4)$ & $3(7.7)$ & $7(4.8)$ & 0.47 \\
\hline Major + life-threatening bleeding & $49(26.3)$ & $10(25.6)$ & $39(26.5)$ & 0.91 \\
\hline Major + minor bleeding & $75(40.3)$ & $15(38.5)$ & $60(40.8)$ & 0.79 \\
\hline Major bleeding & $46(24.7)$ & $10(25.6)$ & $36(24.7)$ & 0.9 \\
\hline Minor bleeding & $29(15.6)$ & $5(12.8)$ & $24(16.3)$ & 0.59 \\
\hline Need for transfusion & $54(29)$ & $13(33.3)$ & $41(27.9)$ & 0.51 \\
\hline Any stroke or TIA & $19(10.2)$ & $7(17.9)$ & $12(8.2)$ & 0.07 \\
\hline Stroke & $13(7)$ & $5(12.8)$ & $8(5.4)$ & 0.11 \\
\hline
\end{tabular}

$A R$ - aortic regurgitation, BMI - body mass index, BSA - body surface area, GFR-glomerular filtration rate, COPD - chronic obstructive pulmonary disease, LVEF-left ventricle ejection fraction, MR - mitral regurgitation, NYHA - New York Heart Association, PS - protamine sulfate, TIA - transient ischemic attack, UFH - unfractionated heparin. 
Table II. Uni- and multivariate logistic regression analysis of major bleeding occurrence

\begin{tabular}{|c|c|c|c|c|c|c|}
\hline \multirow[t]{2}{*}{ Parameter } & \multicolumn{3}{|c|}{ Univariate } & \multicolumn{3}{|c|}{ Multivariate } \\
\hline & OR & $\mathrm{Cl}$ & $P$-value & OR & $\mathrm{Cl}$ & $P$-value \\
\hline \multicolumn{7}{|l|}{ Demographics: } \\
\hline Female gender, $n(\%)$ & 2.07 & $1.04-4.14$ & 0.04 & 2.18 & $1.08-4.4$ & 0.03 \\
\hline Age, mean \pm SD [years] & 1.03 & $0.98-1.08$ & 0.25 & & & \\
\hline \multicolumn{7}{|l|}{ Baseline characteristics: } \\
\hline $\mathrm{BMI}$, mean $\pm \mathrm{SD}\left[\mathrm{kg} / \mathrm{m}^{2}\right]$ & 0.94 & $0.86-1.02$ & 0.12 & 0.93 & $0.85-1.01$ & 0.09 \\
\hline Hypertension, $n(\%)$ & 1.5 & $0.68-3.51$ & 0.3 & & & \\
\hline Diabetes, $n(\%)$ & 0.69 & $0.34-1.41$ & 0.31 & & & \\
\hline GFR $<30 \mathrm{ml} / \mathrm{min}, n(\%)$ & 1.29 & $0.43-3.88$ & 0.65 & & & \\
\hline History of bleeding, $n(\%)$ & 0.9 & $0.24-3.4$ & 0.88 & & & \\
\hline Coronary artery disease, $n(\%)$ & 0.85 & $0.43-1.67$ & 0.64 & & & \\
\hline \multicolumn{7}{|l|}{ History of stroke/TIA, $n(\%)$} \\
\hline Atrial fibrillation, $n(\%)$ & 1.26 & $0.63-2.51$ & 0.51 & & & \\
\hline COPD, $n(\%)$ & 0.75 & $0.3-1.85$ & 0.52 & & & \\
\hline NYHA class 3-4, $n(\%)$ & 1.4 & $0.71-2.72$ & 0.33 & & & \\
\hline LVEF, mean \pm SD \% & 0.99 & $0.96-1.01$ & 0.28 & & & \\
\hline \multicolumn{7}{|l|}{$M R \geq 3$} \\
\hline Serum creatinine, mean \pm SD [mg/dl] & 1.0 & $0.69-1.46$ & 0.99 & & & \\
\hline Hemoglobin, mean \pm SD [g/dl] & 0.86 & $0.69-1.06$ & 0.16 & 0.92 & $0.73-1.15$ & 0.44 \\
\hline \multicolumn{7}{|l|}{ Procedural data: } \\
\hline General anesthesia, $n(\%)$ & 1.52 & $0.71-3.27$ & 0.28 & & & \\
\hline Closure device, $n(\%)$ & 0.81 & $0.41-1.57$ & 0.52 & & & \\
\hline UFH, mean \pm SD [IU] & 0.99 & $0.84-1.18$ & 0.96 & & & \\
\hline UFH/kg, mean \pm SD [IU] & 1.01 & $0.99-1.03$ & 0.15 & 1.01 & $0.99-1.02$ & 0.45 \\
\hline Balloon-expandable prosthesis, $n$ (\%) & 0.76 & $0.38-1.54$ & 0.45 & & & \\
\hline \multicolumn{7}{|l|}{ AR post-TAVI, grade $\geq 3, n(\%)$} \\
\hline Protamine sulfate use, $n(\%)$ & 1.05 & $0.47-2.37$ & 0.9 & & & \\
\hline
\end{tabular}

$A R$ - aortic regurgitation, BMI - body mass index, GFR - glomerular filtration rate, COPD - chronic obstructive pulmonary disease, CI - confidence interval, $I U$-international units, LVEF-left ventricle ejection fraction, MR - mitral regurgitation, NYHA - New York Heart Association, OR - odds ratio, TIA - transient ischemic attack, UFH - unfractionated heparin.

bleeding complications, irrespective of the approach - surgical cutdown or percutaneous access with closure device.

Since the initial studies assessing the feasibility and efficacy of TAVI, protamine sulfate administration has always been recommended [1] as a natural antidote to UFH with little or no consideration for the potential rebound anticoagulation due to PS short half-life $(7 \mathrm{~min}$ as compared to heparin's 60-90 $\mathrm{min}$ ) as well as possible rebound thrombosis after sudden UFH reversal [13]. Despite the unpredictability of the PS effect as well as the well-proven negative impact of bleeding complications on survival [9], PS has never undergone scrutiny in the TAVI setting; therefore its true impact on bleeding complications remains uncertain.

Furthermore, a pro-thromboembolic effect of the PS cannot be excluded. In a randomized-controlled trial assessing UFH neutralization after a carotid endarterectomy, Fearn et al. concluded that reversing UFH with PS may predispose to thrombosis of the internal carotid artery and stroke [5]. In our study, a numerically higher stroke and TIA rate was observed in patients receiving PS. This along with absence of an impact on bleeding rates, 
Table III. Uni- and multivariate logistic regression analysis of the composite of major and minor bleeding endpoint occurrence

\begin{tabular}{|c|c|c|c|c|c|c|}
\hline \multirow[t]{2}{*}{ Parameter } & \multicolumn{3}{|c|}{ Univariate } & \multicolumn{3}{|c|}{ Multivariate } \\
\hline & OR & $\mathrm{Cl}$ & $P$-value & OR & $\mathrm{Cl}$ & $P$-value \\
\hline \multicolumn{7}{|l|}{ Demographics: } \\
\hline Female gender, $n(\%)$ & 2.33 & $1.28-4.26$ & 0.01 & 2.01 & $1.06-3.84$ & 0.03 \\
\hline Age, mean \pm SD [years] & 1.01 & $0.97-1.05$ & 0.75 & & & \\
\hline \multicolumn{7}{|l|}{ Baseline characteristics: } \\
\hline $\mathrm{BMI}$, mean $\pm \mathrm{SD}\left[\mathrm{kg} / \mathrm{m}^{2}\right]$ & 0.95 & $0.89-1.02$ & 0.19 & & & \\
\hline Hypertension, $n$ (\%) & 1.43 & $0.72-2.85$ & 0.31 & & & \\
\hline Diabetes, $n(\%)$ & 1.28 & $0.69-2.35$ & 0.42 & & & \\
\hline GFR < $30 \mathrm{ml} / \mathrm{min}, n(\%)$ & 1.04 & $0.38-2.87$ & 0.94 & & & \\
\hline History of bleeding, $n(\%)$ & 1.8 & $0.58-5.59$ & 0.31 & & & \\
\hline Coronary artery disease, $n(\%)$ & 0.88 & $0.49-1.6$ & 0.68 & & & \\
\hline History of stroke/TIA, $n$ (\%) & 1.27 & $0.58-2.76$ & 0.55 & & & \\
\hline Atrial fibrillation, $n(\%)$ & 1.04 & $0.56-1.9$ & 0.9 & & & \\
\hline COPD, $n(\%)$ & 0.85 & $0.4-1.8$ & 0.67 & & & \\
\hline NYHA class 3-4, n (\%) & 1.3 & $0.71-2.3$ & 0.42 & & & \\
\hline LVEF, mean \pm SD \% & 0.99 & $0.98-1.02$ & 0.9 & & & \\
\hline LVEF $<40 \%$ & 1.03 & $0.52-2.05$ & 0.93 & & & \\
\hline Serum creatinine, mean \pm SD [mg/dl] & 0.89 & $0.62-1.28$ & 0.53 & & & \\
\hline Hemoglobin, mean \pm SD [g/dl] & 0.81 & $0.67-0.98$ & 0.03 & 0.84 & $0.68-1.03$ & 0.09 \\
\hline \multicolumn{7}{|l|}{ Procedural data: } \\
\hline General anaesthesia, $n$ (\%) & 1.92 & $0.98-3.74$ & 0.054 & 2.23 & $1.13-4.63$ & 0.02 \\
\hline Closure device, $n(\%)$ & 1.21 & $0.67-2.18$ & 0.53 & & & \\
\hline UFH, mean \pm SD [IU] & 1.06 & $0.91-1.24$ & 0.44 & & & \\
\hline UFH/kg, mean \pm SD [IU] & 1.02 & $1.0-1.03$ & 0.04 & 1.02 & $1.0-1.03$ & 0.02 \\
\hline Balloon-expandable prosthesis, $n(\%)$ & 0.84 & $0.46-1.54$ & 0.57 & & & \\
\hline AR post-TAVI, grade $\geq 3, n(\%)$ & 1.19 & $0.55-2.56$ & 0.66 & & & \\
\hline Protamine sulfate use, $n(\%)$ & 0.91 & $0.44-1.87$ & 0.79 & & & \\
\hline
\end{tabular}

$A R$ - aortic regurgitation, BMI - body mass index, GFR - glomerular filtration rate, COPD - chronic obstructive pulmonary disease, CI - confidence interval, $I U$-international units, LVEF-left ventricle ejection fraction, MR - mitral regurgitation, NYHA - New York Heart Association, OR-odds ratio, TIA - transient ischemic attack, UFH - unfractionated heparin.

should prompt caution and further investigation of protamine sulfate use in TAVI patients.

\section{Protamine sulfate administration}

Recommendations regarding UFH reversal with PS are based on an expert consensus from 2012 and advice to reverse UFH with PS in the case of transapical TAVIs as well as transfemoral ones with the exception of cases with minimal bleeding risk - they do not, however, define the minimal bleeding risk. In reality, centers around the world undertake an individual approach and some use PS routinely [3], while others do so only in selected cases [4].

In our analysis, $21 \%$ of the overall population received PS at the end of the procedure, while in the subgroup of patients treated via percutaneous access the percentage was $30.8 \%$. The data regarding the exact rate of protamine administration are rarely reported and therefore difficult to compare. In a study assessing ACT-guided UFH administration, Bernelli et al. reported 
Table IV. Uni- and multivariate logistic regression analysis of stroke or TIA occurrence

\begin{tabular}{|c|c|c|c|c|c|c|}
\hline \multirow[t]{2}{*}{ Parameter } & \multicolumn{3}{|c|}{ Univariate } & \multicolumn{3}{|c|}{ Multivariate } \\
\hline & OR & $\mathrm{Cl}$ & $P$-value & OR & $\mathrm{Cl}$ & $P$-value \\
\hline \multicolumn{7}{|l|}{ Demographics: } \\
\hline Female gender, $n(\%)$ & 0.83 & $0.32-2.14$ & 0.69 & & & \\
\hline Age, mean \pm SD [years] & 0.97 & $0.92-1.03$ & 0.39 & & & \\
\hline \multicolumn{7}{|l|}{ Baseline characteristics: } \\
\hline $\mathrm{BMI}$, mean $\pm \mathrm{SD}\left[\mathrm{kg} / \mathrm{m}^{2}\right]$ & 1.01 & $0.89-1.1$ & 0.94 & & & \\
\hline Hypertension, $n(\%)$ & 1.91 & $0.53-0.68$ & 0.32 & & & \\
\hline Diabetes, $n(\%)$ & 2.09 & $0.8-5.43$ & 0.13 & & & \\
\hline Coronary artery disease, $n$ (\%) & 2.07 & $0.71-0.6 .01$ & 0.18 & & & \\
\hline History of stroke/TIA, $n$ (\%) & 3.5 & $1.24-9.7$ & 0.02 & 3.85 & $1.31-11.3$ & 0.01 \\
\hline Atrial fibrillation, $n$ (\%) & 1.07 & $0.39-2.86$ & 0.89 & & & \\
\hline COPD, $n(\%)$ & 0.79 & $0.22-2.9$ & 0.72 & & & \\
\hline NYHA class 3-4, n (\%) & 1.96 & $0.73-5.2$ & 0.18 & & & \\
\hline LVEF, mean \pm SD \% & 1.04 & $1-1.08$ & 0.07 & 1.04 & $1-1.09$ & 0.08 \\
\hline LVEF $<40 \%$ & 0.57 & $0.16-2.08$ & 0.4 & & & \\
\hline Serum creatinine, mean $\pm \mathrm{SD}[\mathrm{mg} / \mathrm{dl}]$ & 0.82 & $0.39-1.7$ & 0.59 & & & \\
\hline Hemoglobin, mean \pm SD [g/dl] & 0.83 & $0.62-1.12$ & 0.23 & & & \\
\hline \multicolumn{7}{|l|}{ Procedural data: } \\
\hline General anesthesia, $n$ (\%) & 0.95 & $0.34-2.65$ & 0.93 & & & \\
\hline Closure device, $n$ (\%) & 1.39 & $0.52-3.73$ & 0.5 & & & \\
\hline UFH, mean \pm SD [IU] & 1.11 & $0.86-1.4$ & 0.43 & & & \\
\hline UFH/kg, mean \pm SD [IU] & 0.99 & $0.97-1.02$ & 0.7 & & & \\
\hline Balloon-expandable prosthesis, $n(\%)$ & 0.29 & $0.08-1.02$ & 0.05 & 0.25 & $0.07-0.92$ & 0.04 \\
\hline AR post-TAVI, grade $\geq 3, n(\%)$ & 1.32 & $0.41-4.3$ & 0.64 & & & \\
\hline Protamine sulfate use, $n$ (\%) & 2.46 & $0.89-6.75$ & 0.08 & 1.89 & $0.6-5.58$ & 0.25 \\
\hline
\end{tabular}

$A R$ - aortic regurgitation, $B M I$ - body mass index, GFR - glomerular filtration rate, COPD - chronic obstructive pulmonary disease, CI - confidence interval, IU international units, LVEF - left ventricle ejection fraction, MR - mitral regurgitation, NYHA - New York Heart Association, OR - odds ratio, TIA - transient ischemic attack, UFH - unfractionated heparin.

Table V. Impact of protamine sulfate administration on primary and secondary endpoints occurrence

\begin{tabular}{lccc} 
Parameter & OR & Cl & $P$-value \\
\hline 30-day all-cause mortality & 1.67 & $0.41-6.8$ & 0.48 \\
\hline Major + life-threatening bleeding* & 0.95 & $0.43-2.14$ & 0.91 \\
\hline Major + minor bleeding* & 0.91 & $0.44-1.87$ & 0.79 \\
\hline Major bleeding* & 1.05 & $0.47-2.37$ & 0.9 \\
\hline Minor bleeding* & 0.75 & $0.27-2.1$ & 0.59 \\
\hline Need for transfusion $^{*}$ & 1.29 & $0.61-2.75$ & 0.51
\end{tabular}

${ }^{*}$ At 48 h. TIA - transient ischemic attack. 
that $16.3 \%$ of patients have received PS [14]. The mean protamine sulfate dose in our study $-0.48 \mathrm{mg} / 100 \mathrm{IU}$ UFH - seems plausible in light of UFH's half-life time of 60-90 min and the ability of $1 \mathrm{mg}$ of PS to neutralize 100 IU UFH [15]. Patients receiving PS more often underwent procedures with closure devices and received more unfractionated heparin per $\mathrm{kg}$ of body weight. The first finding is most likely a result of a more confident hemostasis achieved during a surgical cut-down approach. The tendency to administer PS in patients who have received a higher dose of anticoagulation is self-explanatory. The overall lower ejection fraction in patients not receiving PS may be due to the known negative impact of PS on blood pressure and hemodynamics [16].

\section{Bleeding complications}

The rate of major bleeding complications of $24.7 \%$ is higher than in randomized-controlled trials, but in line with real-life cohorts of TAVI patients $[4,13,17]$ - in a meta-analysis of 3519 patients, the reported rate of bleeding complications according to VARC criteria ranged from $26.8 \%$ to $77 \%$ [18]. Multivariate logistic regression analysis identified female sex as an independent predictor of primary endpoint. A number of studies have shown an increase in bleeding and vascular complications among women undergoing percutaneous procedures in general [19-21]. A negative impact of female gender on bleeding complications after TAVI was previously demonstrated by the Paris-Rotterdam-Milano-Toulouse in Collaboration (PRAGMATIC) group - in their analysis of 986 patients, female sex doubled the risk of life-threatening and disabling bleeding events and increased the risk of vascular complications by $60 \%$ [22]. In a multivariate analysis of the composite of major and minor bleeding occurrence in addition to female gender, also GA and the number of IU of UFH per kg were identified as independent endpoint predictors. In the majority of studies comparing general anesthesia and conscious sedation there are no significant differences in terms of bleeding complication rate [23]. Although Gauthier et al. reported a significantly higher number of vascular complications, the difference in bleeding complications was only nominal [3]. Brecker et al. reported a similar rate of bleeding among 490 propensity-matched GA and conscious sedation TAVI patients [24]. In the so far unpublished SOLVE-TA$\mathrm{VI}$ randomized trial assessing anesthesia types, bleeding complications were not part of the primary or secondary endpoints [25]. The impact of body-weight-adjusted unfractionated heparin dose on bleeding has been shown in the past, including our own material [26]. In a previously mentioned study, non-ACT guided UFH administration resulted in significantly higher UFH doses and was associated with an almost six-fold increase in bleeding complication rates [13].

\section{Limitations}

The main limitation of our study is its relatively small sample size and retrospective character. Incorporating transfemoral procedures performed via surgical cutdown and percutaneously with device closure with the inherent differences between the two methods could have influenced the results. Study endpoints were collected retrospectively and not independently adjudicated. The decision-making process behind PS administration was not documented. The exclusion of periprocedural deaths precluded a meaningful analysis of the impact of bleeding complications on mortality.

\section{Conclusions}

In this retrospective analysis, protamine sulfate administration did not decrease the primary endpoint rate. Female gender predicted major bleeding complications. Randomized, placebo-controlled trials are required to accurately assess the impact of protamine sulfate.

\section{Conflict of interest}

The authors declare no conflict of interest.

\section{References}

1. Mack MJ, Leon MB, Thourani VH, et al. Transcatheter aortic-valve replacement with a balloon-expandable valve in low-risk patients. N Engl J Med 2019; 380: 1695-705.

2. Holmes DR Jr, Mack MJ, Kaul S, et al. 2012 ACCF/AATS/SCAI/ STS expert consensus document on transcatheter aortic valve replacement: developed in collabration with the American Heart Association, American Society of Echocardiography, European Association for Cardio-Thoracic Surgery, Heart Failure Society of America, Mended Hearts, Society of Cardiovascular Anesthesiologists, Society of Cardiovascular Computed Tomography, and Society for Cardiovascular Magnetic Resonance. J Thorac Cardiovasc Surg 2012; 144: e29-84.

3. Gauthier C, Astarci P, Baele P, et al. Mid-term survival after transcatheter aortic valve implantation: results with respect to the anesthetic management and to the access route (transfemoral versus transapical). Ann Card Anaesth 2015; 18: 343-51.

4. Borz B, Durand E, Godin M, et al. Incidence, predictors and impact of bleeding after transcatheter aortic valve implantation using the balloon-expandable Edwards prosthesis. Heart 2013; 99: 860-5.

5. Fearn SJ, Parry AD, Picton AJ, et al. Should heparin be reversed after carotid endarterectomy? A randomized prospective trial. Eur J Vasc Endovasc Surg 1997; 13: 394-7.

6. Levison JA, Faust GR, Halpern VJ, et al. Relationship of protamine dosing with postoperative complications of carotid endarterectomy. Ann Vasc Surg 1999; 13: 67-72.

7. Cosgrave J, Qasim A, Latib A, et al. Protamine usage following implantation of drug-eluting stents: a word of caution. Catheter Cardiovasc Interv 2008; 71: 913-4.

8. Kappetein AP, Head SJ, Généreux P, et al. Updated standardized endpoint definitions for transcatheter aortic valve implantation: the Valve Academic Research Consortium-2 consensus document (VARC-2). Eur J Cardiothorac Surg 2012; 42: S45-60. 
9. Rodés-Cabau J, Dauerman HL, Cohen MG, et al. Antithrombotic treatment in transcatheter aortic valve implantation: insights for cerebrovascular and bleeding events. J Am Coll Cardiol 2013; 62: 2349-59.

10. Linke A, Gerckens U, Wenaweser P, et al. Treatment of high risk aortic stenosis patients with transcatheter Medtronic CoreValve implantation: results from the international multicenter ADVANCE study. J Am Coll Cardiol 2012; 59: e8.

11. Meredith IT. Australia-New Zealand CoreValve transcatheter aortic valve study. Presented at: Transcatheter Valve Therapies: An Advanced Scientific and Clinical Workshop; June 2-5, 2012; Seattle, Washington.

12. Bosmans JM, Kefer J, De Bruyne B, et al. Procedural, 30-day and one year outcome following CoreValve or Edwards transcatheter aortic valve implantation: results of the Belgian national registry. Interact Cardiovasc Thorac Surg 2011; 12: 762-7.

13. Sergie Z, Lefèvre T, Van Belle E, et al. Current periprocedural anticoagulation in transcatheter aortic valve replacement: could bivalirudin be an option? Rationale and design of the BRAVO 2/3 studies. J Thromb Thrombolysis 2013; 35: 483-93.

14. Bernelli C, Chieffo A, Montorfano M, et al. Usefulness of baseline activated clotting time-guided heparin administration in reducing bleeding events during transfemoral transcatheter aortic valve implantation. JACC Cardiovasc Interv 2014; 7: 140-51.

15. Garcia DA, Baglin TP, Weitz J, et al. Parenteral anticoagulants: Antithrombotic Therapy and Prevention of Thrombosis, 9th ed: American College of Chest Physicians Evidence-Based Clinical Practice Guidelines. Chest 2012; 141 (2 Suppl): e24S-43S.

16. Welsby IJ, Newman MF, Phillips-Bute B, et al. Hemodynamic changes after protamine administration: association with mortality after coronary artery bypass surgery. Anesthesiology 2005; 102: 308-14.

17. Stortecky S, Stefanini GG, Pilgrim T, et al. Validation of the valve academic research consortium bleeding definition in patients with severe aortic stenosis undergoing transcatheter aortic valve implantation. J Am Heart Assoc 2015; 4: e002135.

18. Généreux P, Head SJ, Van Mieghem NM, et al. Clinical outcomes after transcatheter aortic valve replacement using valve academic research consortium definitions: a weighted meta-analysis of 3,519 patients from 16 studies. J Am Coll Cardiol 2012; 59: 2317-26.

19. Piper WD, Malenka DJ, Ryan TJ Jr, et al. Predicting vascular complications in percutaneous coronary interventions. Am Heart 2003; 145: 1022-9.

20. Peterson ED, Lansky AJ, Kramer J, Anstrom K, Lanzilotta MJ. Effect of gender on the outcomes of contemporary percutaneous coronary intervention. Am J Cardiol 2001; 88: 359-64.

21. Argulian E, Patel AD, Abramson JL, et al. Gender differences in short-term cardiovascular outcomes after percutaneous coronary interventions. Am J Cardiol 2006; 98: 48-53.

22. Van Mieghem NM, Tchetche D, Chieffo A, et al. Incidence, predictors, and implications of access site complications with transfemoral transcatheter aortic valve implantation. Am J Cardiol 2012; 110: 1361-7.

23. O' Sullivan KE, Bracken-Clarke D, Segurado R, et al. Is local anesthesia the optimum strategy in retrograde transcatheter aortic valve implantation? A systematic review and meta-analysis. Thorac Cardiovasc Surg 2014; 62: 489-97.

24. Brecker SJ, Bleiziffer S, Bosmans J, et al. Impact of anesthesia type on outcomes of transcatheter aortic valve implantation (from the Multicenter ADVANCE Study). Am J Cardiol 2016; 117 : 1332-8.

25. Thiele H. A $2 \times 2$ randomized trial of self-expandable vs balloon-expandable valves and general vs local anesthesia in patients undergoing transcatheter aortic valve implantation. Presented at: TCT 2018. September 23, 2018. San Diego, CA.

26. Rymuza B, Zbroński K, Scisło P, et al. Thromboelastography for predicting bleeding in patients with aortic stenosis treated with transcatheter aortic valve implantation. Kardiol Pol 2018; 76 : 418-25. 